\title{
Prognostic implications of coronary calcification in patients with obstructive coronary artery disease treated by percutaneous coronary intervention: a patient-level pooled analysis of 7 contemporary stent trials
}

\author{
Christos V Bourantas, ${ }^{1}$ Yao-Jun Zhang, ${ }^{1}$ Scot Garg, ${ }^{2}$ Javaid Iqbal, ${ }^{1}$ Marco Valgimigli, ${ }^{1}$ \\ Stephan Windecker, ${ }^{3}$ Friedrich W Mohr, ${ }^{4}$ Sigmund Silber, ${ }^{5}$ Ton de Vries, ${ }^{6}$ \\ Yoshinobu Onuma, ${ }^{1}$ Hector M Garcia-Garcia, ${ }^{1}$ Marie-Angele Morel, ${ }^{6}$ \\ Patrick W Serruys ${ }^{1,7}$
}

For numbered affiliations see end of article.

\section{Correspondence to} Patrick W S Serruys, Erasmus MC, Thoraxcenter, Head of Dept of Interventional Cardiology, Thoraxcenter Ba583, Rotterdam 3015 GD Netherlands:

p.w.j.c.serruys@erasmusmc.nl

CVB and Y-JZ have contributed equally to this study.

Received 4 November 2013 Revised 7 April 2014 Accepted 23 April 2014 Published Online First 20 May 2014

\section{ABSTRACT}

Objective To investigate the long-term prognostic implications of coronary calcification in patients undergoing percutaneous coronary intervention for obstructive coronary artery disease.

Methods Patient-level data from 6296 patients enrolled in seven clinical drug-eluting stents trials were analysed to identify in angiographic images the presence of severe coronary calcification by an independent academic research organisation (Cardialysis, Rotterdam, The Netherlands). Clinical outcomes at 3-years follow-up including all-cause mortality, death-myocardial infarction (MI), and the composite end-point of all-cause death-Ml-any revascularisation were compared between patients with and without severe calcification. Results Severe calcification was detected in $20 \%$ of the studied population. Patients with severe lesion calcification were less likely to have undergone complete revascularisation ( $48 \%$ vs $55.6 \%, \mathrm{p}<0.001)$ and had an increased mortality compared with those without severely calcified arteries ( $10.8 \%$ vs $4.4 \%, p<0.001$ ). The event rate was also high in patients with severely calcified lesions for the combined end-point death-MI (22.9\% vs $10.9 \% ; \mathrm{p}<0.001)$ and death-Ml- any revascularisation (31.8\% vs $22.4 \%$; $p<0.001)$. On multivariate Cox regression analysis, including the Syntax score, the presence of severe coronary calcification was an independent predictor of poor prognosis (HR: 1.33 $95 \% \mathrm{Cl} 1.00$ to $1.77, \mathrm{p}=0.047$ for death; $1.23,95 \%$ $\mathrm{Cl} 1.02$ to $1.49, \mathrm{p}=0.031$ for death-MI, and 1.18, $95 \% \mathrm{Cl} 1.01$ to $1.39, \mathrm{p}=0.042$ for death-Ml- any revascularisation), but it was not associated with an increased risk of stent thrombosis.

Conclusions Patients with severely calcified lesions have worse clinical outcomes compared to those without severe coronary calcification. Severe coronary calcification appears as an independent predictor of worse prognosis, and should be considered as a marker of advanced atherosclerosis.

\section{INTRODUCTION}

From the early days of percutaneous coronary intervention (PCI) it became apparent that the presence of severe coronary calcification was a predictor of worse clinical outcomes. In the era of plain old balloon angioplasty, severe coronary calcification was associated with an increased risk of coronary dissection and procedural failure, while in the bare-metal stent era, it was associated with a higher incidence of in-stent restenosis and target lesions revascularisations (TLR). ${ }^{1}{ }^{2}$ The advent of drug-eluting stents (DES) changed the landscape of coronary intervention through the reduced risk of restenosis and TLR, thereby allowing the interventional treatment of complex lesions and high-risk patients. Several studies have examined the efficacy of DES in heavily calcified lesions reporting mixed results. Some have demonstrated a high success rate and a marked reduction in TLR, while others have reported that patients with calcified lesions undergoing PCI with DES have a higher incidence of stent thrombosis (ST) and an increased major adverse event rate, compared to the event rate reported in patients without coronary calcification. ${ }^{3-8}$ However, all the previous studies included a small number of patients with few events, ${ }^{48}$ whereas only one has reported the prognostic implications of lesion calcium in patients treated with a second-generation DES. ${ }^{4}$

The aim of the current analysis is to examine the effect of coronary calcification on hard clinical endpoints in patients treated with a first or secondgeneration DES.

\section{METHODS}

\section{Studied population}

We retrospectively analysed data from patients implanted with a DES who were recruited in the following stent trials: the ARTS II (Arterial Revascularisation Therapies Study II), the LEADERS (Limus Eluted From a Durable vs Erodable Stent Coating) trial, the MULTISTRATEGY (Multicenter Evaluation of Single High-Dose Bolus Tirofiban vs Abciximab With Sirolimus-Eluting Stent or Bare-Metal Stent in Acute Myocardial Infarction (MI)) study, the STRATEGY (Single High-Dose Bolus Tirofiban and Sirolimus-Eluting Stent vs Abciximab 
and Bare-Metal Stent in Myocardial Infarction) trial, the SIRTAX (Sirolimus-Eluting Stent Compared With Paclitaxel-Eluting Stent for Coronary Revascularization), the SYNTAX (Synergy Between Percutaneous Coronary Intervention with Taxus and Cardiac Surgery) and the RESOLUTE (Resolute All Comers) trial. The aim and inclusion criteria were different between studies: two trials included stable patients with complex coronary artery disease and aimed to compare outcomes between patients treated with PCI or bypass surgery (the SYNTAX and the ARTS II), two evaluated the efficacy of DES treatment combined with different IIb/IIIa inhibitors in patients admitted with an acute MI (the STRATEGY and MYLTISTRATEGY trial), the SIRTAX assessed the effectiveness of two first-generation DES devices in patients with obstructive coronary artery disease that was amenable to PCI, the LEADERS compared a DES with a biodegradable polymer to a firstgeneration DES in patients with coronary artery disease and, finally, the RESOLUTE all-comers compared two secondgeneration DES with different drug elution in an unselected patient population which was representative of patients treated in everyday clinical practice. A detailed description of each study design has been reported elsewhere. ${ }^{9-15}$ All studies complied with the Declaration of Helsinki, and were approved by the ethical review board of the institution involved, whereas, the included patients provided written informed consent for participation in these studies.

\section{Data processing}

The baseline demographic data and the X-ray angiographic data of the patients recruited in these studies were transferred to an independent academic research organisation (Cardialysis, Rotterdam, The Netherlands) for further processing. Two trained analysts reviewed the angiographic films; they calculated the Syntax score using a previously described methodology, and identified the presence of severely calcified lesions defined as: radiopacities noted without cardiac motion before contrast injection, generally compromising both sides of the arterial lumen. ${ }^{16}$ In case of disagreement, the opinion of a third expert analyst was requested, and the final decision was obtained by consensus. At the time of the angiographic analysis, the reviewers were blinded to the patients' demographic characteristics and clinical outcomes.

\section{Clinical end-points and definitions}

All the studied patients were followed-up for at 3 years. The primary end-point of this analysis was all-cause mortality at 3 years follow-up. Secondary end-points of this analysis were the combined end-points for death-all MIs (ST-elevation and non-ST-elevation $\mathrm{MI}$ - - and the composite end-point for-MIany revascularisation. As it has been previously reported, there was an inconsistency in the definition of ST-elevation and non-ST-elevation MI among the different studies, which can be attributed to the different populations included in each study, the different study designs, and the different periods when the trials were conducted. ${ }^{18}$ Considering the fact that the events reported in each trial were reviewed by an independent clinical event committee a decision was taken not to readjudicate MI using a uniform definition and, instead, all MIs are defined as per the individual study protocol definition. Revascularisation follow-up data were available in only 4 (ARTS II, SYNTAX, LEADERS, and RESOLUTE) studies and, thus, the combined end-point all-cause mortality-any $\mathrm{MI}$-any revascularisation was reported only for the patients recruited in these studies.

Additionally, the ST events were recorded and compared in the two groups. ST was classified as definite, probable and possible, according to the Academic Research Consortium definitions. ${ }^{19}$ Definite ST data were available in six studies (ARTS II, SYNTAX, LEADERS, RESOLUTE, MULTISTRATEGY and SIRTAX), probable ST data in 5 (ARTS II, SYNTAX, LEADERS, RESOLUTE, and MULTISTRATEGY), and the possible in 4 (ARTS II, SYNTAX, LEADERS, and RESOLUTE) out of the seven clinical trials.

\section{Statistics}

Numerical variables are presented as median with 25 th and 75 th percentiles while categorical variables are presented as absolute values and percentages. The studied patients were categorised into those with severely calcified coronary lesions and those without severe lesion calcification. Comparisons between the two groups were performed using the Mann-Whitney U test for the continuous variables, and the $\chi^{2}$ test for the categorical variables.

Cox regression analysis was used to identify predictors of adverse events, that is, all-cause mortality,-MI, death-MI-any revascularisation, and ST. The hazard ratio (HR) and the 95\% confidence interval (CI) for the continuous variables were estimated per unit increase. The estimates from the univariate analysis predictors of worse prognosis were entered into a multivariable model to identify independent predictors of worse outcomes. In the multivariable models, the 'forced enter' method was deemed appropriate. To address the clustering effect, shared frailty models were used in univariate and multivariate analyses. To exclude colinearity, we identified the variables that were highly correlated $(r>0.5$ and $p<0.05)$, and we included in the model only those variables that had a higher level of prognostic significance.

The proportionality of hazards assumption was examined by residual plotting. Graphical plots were made by the Kaplan-Meier method. The log-rank statistic was used to compare prognosis between the two groups. A p value $<0.05$ (two-tailed) was considered statistically significant. Data analysis was performed using the Statistical Package for Social Sciences (SPSS) V.18.0 (SPSS, Chicago, Illinois, USA) and the STATA V.12.0 software (Stata, College Station, Texas, USA).

\section{RESULTS}

\section{Baseline demographics}

The Syntax score, and the clinical and the follow-up data were available for 6296 patients out of the 7639 patients that were enrolled in the seven clinical trials. Most of the studied patients were male with a history of hypertension and hypercholesterolaemia and were admitted because of an acute coronary event. Four out of 10 patients were treated with a first-generation DES (ie, a sirolimus or paclitaxel-eluting stent), and six out of 10 patients with a second-generation device (ie, an everolimus, zotarolimus, or a biolimus-eluting platform).

Twenty per cent of the studied patients had severely calcified lesions on coronary angiography (table 1). These patients were older and were more likely to suffer from hypertension and hypercholesterolaemia compared to the group of patients without severe lesion calcium who were more often diabetic. Patients with severe calcification had a higher Syntax score (12.1 units higher than those without severe calcification, 95\% CI 11.5 to 12.7 ; $\mathrm{p}<0.001$ ), and were less likely to have undergone complete revascularisation (data with regards complete revascularisation was available only for the ARTS II the STRATEGY, MULTISTRATEGY and the SYNTAX study). No differences were noted between the two groups with regards to the cause of admission, the incidence of LV systolic dysfunction, and the prevalence of peripheral vascular disease (PVD). 
Table 1 Baseline demographics of the patients with and without severely calcified lesions

\begin{tabular}{|c|c|c|c|c|}
\hline & $\begin{array}{l}\text { All studied patients } \\
(n=6296)\end{array}$ & $\begin{array}{l}\text { Patients with severely calcified } \\
\text { lesions }(n=1291)\end{array}$ & $\begin{array}{l}\text { Patients without severe } \\
\text { calcifications }(n=5005)\end{array}$ & p Value \\
\hline Age (years) & $64(56-72)$ & $69(62-75)$ & $63(55-71)$ & $<0.001$ \\
\hline Male (\%) & $4740(75.3)$ & $957(74.1)$ & $3783(75.6)$ & 0.280 \\
\hline BMI & $27.1(24.7-30.0)$ & $27.0(24.2-30.0)$ & $27.2(24.8-30.1)$ & 0.001 \\
\hline Hypertension & $4328(69.4)$ & $969(75.5)$ & $3359(67.7)$ & $<0.001$ \\
\hline Hypercholesterolaemia (\%) & $4056(65.2)$ & $899(70.2)$ & $3157(63.9)$ & $<0.001$ \\
\hline Diabetes mellitus (\%) & $1453(23.2)$ & $1079(21.7)$ & $374(29.0)$ & $<0.001$ \\
\hline Peripheral vascular disease (\%) & $1745(30.7)$ & $397(32.1)$ & $1348(30.3)$ & 0.214 \\
\hline Cerebrovascular disease (\%) & $182(4.9)$ & $73(7.2)$ & $109(4.0)$ & $<0.001$ \\
\hline Creatinine $>200 \mathrm{~mol} / \mathrm{L}$ & $61(1.1)$ & $20(1.6)$ & $41(0.9)$ & 0.025 \\
\hline Positive smoking history (\%) & $3257(52.1)$ & $648(50.4)$ & $2609(52.6)$ & 0.161 \\
\hline LV systolic function & & & & 0.712 \\
\hline Normal LV function (\%) & $3838(78.4)$ & $833(77.6)$ & $3005(78.7)$ & \\
\hline Moderate LV dysfunction (\%) & $865(17.7)$ & $196(18.2)$ & $669(17.5)$ & \\
\hline Severe LV dysfunction (\%) & $191(3.9)$ & $45(4.2)$ & $146(3.8 \%)$ & \\
\hline Unstable presentation (\%) & 3349 (53.2) & $672(52.1)$ & $2677(53.5)$ & 0.357 \\
\hline History of previous MI (\%) & $1745(30.7)$ & 397 (32.1) & $1348(30.3)$ & 0.214 \\
\hline Syntax score & $15(9-23)$ & $25(18-34)$ & $13(7-20)$ & $<0.001$ \\
\hline Complete revascularisation (\%) & $1086(53)$ & $339(48)$ & $550(55.6)$ & 0.001 \\
\hline Treatment with 2 nd generation DES (\%) & $2709(43.0)$ & $375(29.0)$ & $2334(46.5)$ & $<0.001$ \\
\hline
\end{tabular}

BMI, Body Mass Index; MI, myocardial infarction; DES, drug-eluting stent.

\section{Severe lesion calcification and clinical end-points}

All studied patients were followed-up for 3 years. During follow-up, 359 (5.7\%) patients died, of whom 139 had severely calcified lesions (table 2). The Kaplan-Meier analysis showed that patients with severely calcified lesions had significantly higher all-cause mortality $(10.8 \%$ vs $4.4 \%$, log-rank test $=79.35$; $\mathrm{p}<0.001)$ compared to those without. Landmark analysis showed an increased mortality in the group of patients with severely calcified lesions at 1 year post-procedure, and also for the period between 1 and 3 years follow-up (figure 1A).

Table 2 Reported events in the studied patients at a follow-up period of 3 years

\begin{tabular}{|c|c|c|c|}
\hline & $\begin{array}{l}\text { All } \\
\text { studied } \\
\text { patients } \\
(n=6296)\end{array}$ & $\begin{array}{l}\text { Patients with } \\
\text { severely } \\
\text { calcified } \\
\text { lesions } \\
(n=1291)\end{array}$ & $\begin{array}{l}\text { Patients } \\
\text { without } \\
\text { severe } \\
\text { calcifications } \\
(\mathrm{n}=5005)\end{array}$ \\
\hline Death (\%) & $359(5.7)$ & $139(10.8)$ & $220(4.4)$ \\
\hline $\mathrm{MI}(\%)$ & $551(8.8)$ & $183(14.2)$ & $368(7.4)$ \\
\hline Any revascularisation* $(\%)$ & $866(17.3)$ & $241(20.5)$ & $625(16.3)$ \\
\hline \multicolumn{4}{|l|}{ Combined end-points } \\
\hline Death—MI (\%) & $840(13.3)$ & $295(22.9)$ & $545(10.9)$ \\
\hline $\begin{array}{l}\text { Death-MI-any (\%) } \\
\text { revascularisation* }\end{array}$ & $1213(24.2)$ & $373(31.7)$ & $860(22.4)$ \\
\hline \multicolumn{4}{|l|}{ Stent thrombosist } \\
\hline Definite (\%) & $129(2.1)$ & $38(3.0)$ & $91(1.8)$ \\
\hline Probable (\%) & $43(0.8)$ & $16(1.3)$ & $27(0.7)$ \\
\hline Possible (\%) & 97 (1.9) & $35(3.0)$ & $62(1.6)$ \\
\hline \multicolumn{4}{|c|}{$\begin{array}{l}\text { * Revascularisation data were available in } 5018 \text { patients ( } 1175 \text { with severely calcified } \\
\text { lesions and } 3843 \text { in patients without severe coronary calcification). } \\
\text { tDefinite stent thrombosis data were available in } 6222 \text { patients ( } 1279 \text { with severe } \\
\text { lesion calcification and } 4943 \text { without calcified coronaries), probable stent thrombosis } \\
\text { in } 5364 \text { ( } 1221 \text { with severely calcified coronaries and } 4143 \text { without severe coronary } \\
\text { calcification) and possible in } 5034 \text { patients ( } 1182 \text { with severe and } 3852 \text { without } \\
\text { severe coronary calcification). } \\
\text { MI, myocardial infarction. }\end{array}$} \\
\hline
\end{tabular}

Severe calcification appeared as a predictor of increased mortality in the univariate Cox regression analysis (HR: $2.41,95 \%$ CI 1.92 to $3.00 ; \mathrm{p}<0.001)$. Table 3 shows all the predictors of all-cause mortality identified by univariate Cox regression analysis. In the multivariate model, that included all the independent predictors of worse outcomes, apart from the history of cerebrovascular disease and PVD because of missing data, the presence of calcified lesions was independently associated with an increased all-cause mortality (table 3 ).

The combined end-point death-MI was reported in 840 patients. Patients with severe lesion calcification were at a higher risk of experiencing an event compared to those without calcified lesions $(23.2 \%$ vs $11.0 \%$; log-rank $=130.29 ; \mathrm{p}<0.001)$. Landmark analysis showed a worse prognosis in the group of patients with severely calcified lesions at the first year postprocedure, but also for the period between 1 and 3 years follow-up (figure 1B).

In univariate Cox regression analysis, severe calcification was a predictor of death-MI (HR: $1.86,95 \%$ CI 1.60 to 2.16; $\mathrm{p}<0.001)$. In the multivariate model built, excluding the history of cerebrovascular and PVD, severe calcification was a predictor of death-MI (table 4).

Outcome data with regards the combined end-point deathMI-any revascularisation was available in 5018 patients. At 3-year follow-up, 1213 events were reported, of which 860 $(22.4 \%)$ occurred in patients without severely calcified lesions, and $373(31.8 \%)$ in patients with severe lesion calcification $(\log$-rank $=14.55 ; \mathrm{p}<0.001$, figure $1 \mathrm{C})$. Similarly to what has been reported for the other end-points, landmark analysis showed a worse outcome in the group of patients with severely calcified lesions at 1 year post-procedure, and also for the period between 1 and 3 years follow-up (figure 1C). Severe lesion calcification was a predictor of worse outcome in univariate and multivariate Cox regression analysis (table 5).

During follow-up, 269 ST events occurred, of which 129 were definite, 43 probable and 97 possible ST (table 3). Patients with calcified coronaries had an increased incidence of ST 

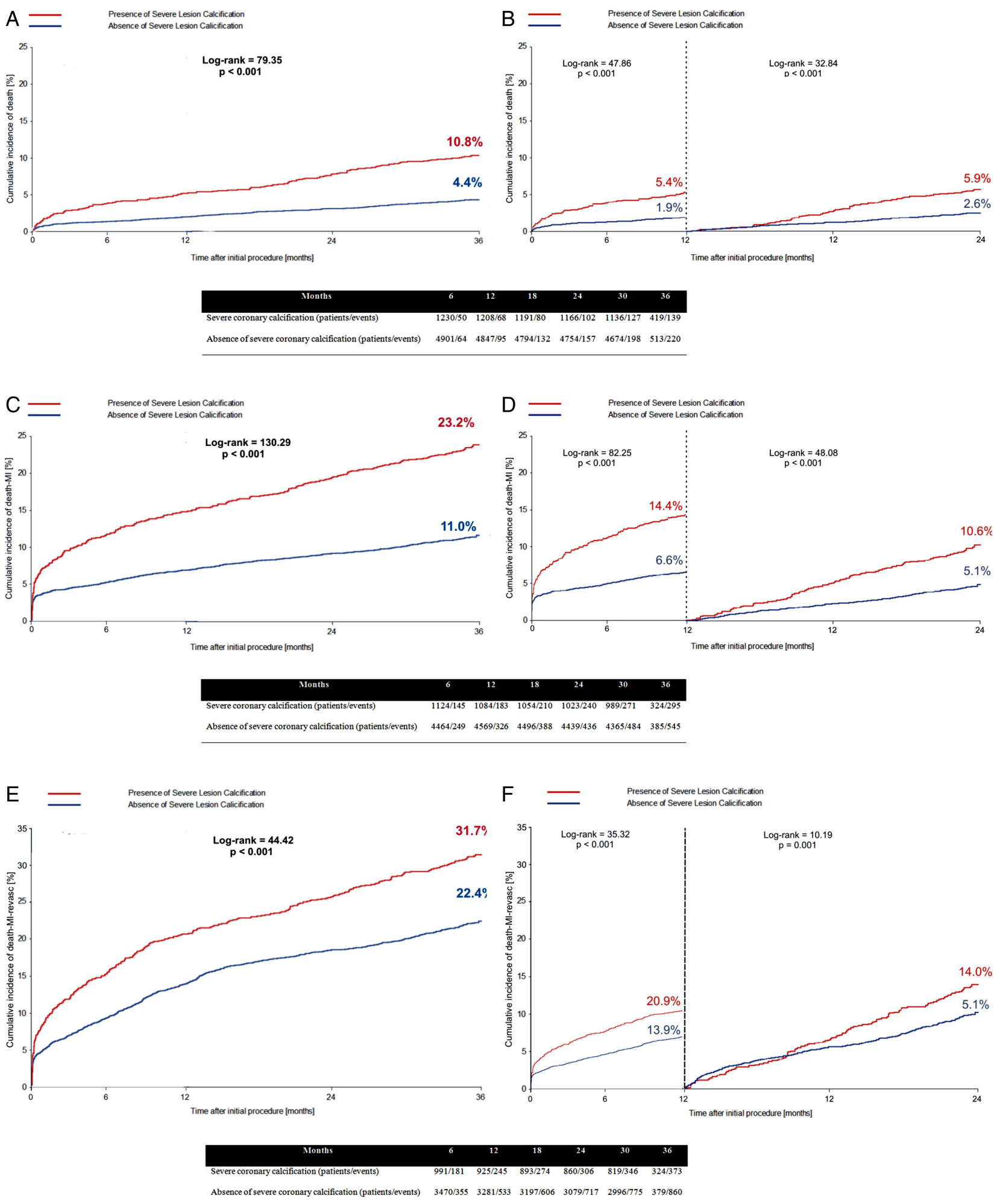

Figure 1 Kaplan-Meier and landmark analysis for the all-cause mortality (A, B), death-myocardial infarction (C, D) and for the combined end-point death-myocardial infarction-any revascularisation $(E, F)$ in patients with and without severe lesion calcification. The landmark analysis was performed for the first year and for the period 1-3 years follow-up.

compared to those without coronary calcification (definite ST: $3 \%$ vs $1.8 \%, \log$-rank $=6.97 ; \mathrm{p}=0.008$; definite/probable ST: $4.3 \%$ vs $2.1 \%, \log$-rank $=17.06, p<0.001)$. Severe lesion calcification was a predictor of ST in univariate analysis (definite ST: HR: $1.66,95 \%$ CI 1.13 to 2.42 ; $<<0.001$; definite/probable ST: HR: $1.95,95 \%$ CI 1.37 to $2.76 ; \mathrm{p}<0.001$ ), but it was not an independent predictor in the multivariate models (definite
ST: HR: $1.41,95 \%$ CI 0.87 to $2.28 ; \mathrm{p}=0.167$; definite/probable ST: HR: $1.40,95 \%$ CI 0.91 to $2.15 ; \mathrm{p}=0.124$ ).

\section{DISCUSSION}

This retrospective analysis provides additional evidence about the prognostic implications of lesion calcium in patients undergoing PCI. We found that severe lesion calcification is an 
Table 3 Univariate and multivariate Cox regression analysis of variables associated with increased all-cause mortality.

\begin{tabular}{|c|c|c|c|c|}
\hline & \multicolumn{2}{|c|}{ Univariate Cox regression } & \multicolumn{2}{|c|}{ Multivariate Cox regression* } \\
\hline & HR $(95 \% \mathrm{Cl})$ & $\mathrm{p}$ Value & HR $(95 \% \mathrm{Cl})$ & p Value \\
\hline Increasing age (per decade) & $2.02(1.81$ to 2.25$)$ & $<0.001$ & 1.76 (1.54 to 2.01$)$ & $<0.001$ \\
\hline Female gender & 1.33 (1.07 to 1.67$)$ & 0.011 & 1.11 (0.85 to 1.46$)$ & 0.438 \\
\hline \multicolumn{5}{|l|}{ Comorbidities } \\
\hline History of diabetes mellitus & 1.85 (1.49 to 2.29$)$ & $<0.001$ & 1.60 (1.24 to 2.06$)$ & $<0.001$ \\
\hline History of hypertension & $1.30(1.03$ to 1.65$)$ & 0.029 & 1.00 (0.74 to 1.35$)$ & 0.991 \\
\hline Absence of history of hypercholesterolaemia & 1.41 (1.14 to 1.74$)$ & 0.002 & 1.16 (0.89 to 1.52 ) & 0.258 \\
\hline History of peripheral vascular disease ${ }^{*}$ & 2.59 (1.80 to 3.63$)$ & $<0.001$ & - & \\
\hline History of cerebrovascular disease* & 1.96 (1.26 to 3.03$)$ & $<0.001$ & - & \\
\hline Increased creatinine (>200 mol/L) & $7.23(4.60$ to 11.36$)$ & $<0.001$ & 3.37 (1.87 to 5.64$)$ & $<0.001$ \\
\hline LV systolic dysfunction & 2.17 (1.83 to 2.59$)$ & $<0.001$ & 1.81 (1.50 to 2.19 ) & $<0.001$ \\
\hline Previous history of myocardial infarction & $1.24(1.00$ to 1.55$)$ & 0.052 & 1.21 (0.93 to 1.56$)$ & 0.154 \\
\hline \multicolumn{5}{|l|}{ Angiographic variables } \\
\hline Syntax score (per unit) & $1.04(1.03$ to 1.05$)$ & $<0.001$ & 1.02 (1.01 to 1.03$)$ & $<0.001$ \\
\hline Severe lesion calcification & 2.41 (1.92 to 3.00$)$ & $<0.001$ & 1.33 (1.00 to 1.77$)$ & 0.047 \\
\hline
\end{tabular}

independent predictor of worse outcomes, and its presence appears to provide additional prognostic information from the Syntax score which reflects coronary artery disease complexity.

Several studies in the past have examined the prognostic implications of lesion calcification in the DES era. Moussa et $a l^{3}$ were the first to show a significant reduction in TLR with paclitaxel-eluting stents compared to bare-metal stents, and no difference in the incidence of TLR between calcified and noncalcified lesions treated with a DES. Kawaguchi et $a l^{7}$ showed a higher risk of in-stent restenosis in calcified lesions but no difference in the incidence of adverse cardiovascular events; however, the small number of patients included in this analysis $(n=380)$, and the lack of multivariate analysis, does not allow us to draw firm conclusions. More recent studies, however, have shown that lesion calcification is associated with an increased risk of cardiovascular events, and provided robust evidence about its prognostic implications. ${ }^{68}$ In all these reports, the patients were mainly treated with a first-generation DES, the prognostic implications of lesion calcification in these studies has been associated with the complexity of the PCI, while the Syntax score which reflects more accurately the anatomical complexity of the lesion was not available.

In this study, we examined for the first time the prognostic implications of lesion calcification in a large group of patients treated with either a first or a second-generation DES. Importantly, we have a reliable and reproducible assessment of lesion complexity as we included in this analysis only the patients that had Syntax score evaluation. We found that lesion calcification provided additional prognostic information as it was an independent predictor of all-cause mortality, death-MI and death-MI-any revascularisation. The fact that the patients with severely calcified lesions have worse prognosis at short term (ie, within the first year post-procedure), and also at long-term follow-up, indicates that the poor outcome in this group of patients is not only related to periprocedural complications.

Table 4 Univariate and multivariate Cox regression analysis of variables associated with the combined end-point death-myocardial infarction

\begin{tabular}{|c|c|c|c|c|}
\hline & \multicolumn{2}{|c|}{ Univariate Cox regression } & \multicolumn{2}{|c|}{ Multivariate Cox regression* } \\
\hline & HR $(95 \% \mathrm{Cl})$ & $\mathrm{p}$ Value & HR $(95 \% \mathrm{Cl})$ & $\mathrm{p}$ Value \\
\hline Increasing age (per decade) & $1.36(1.28$ to 1.45$)$ & $<0.001$ & 1.28 (1.18 to 1.39$)$ & $<0.001$ \\
\hline Female gender & 1.24 (1.07 to 1.44$)$ & 0.004 & $1.08(0.90$ to 1.30$)$ & 0.402 \\
\hline \multicolumn{5}{|l|}{ Comorbidities } \\
\hline History of diabetes mellitus & 1.55 (1.34 to 1.80$)$ & $<0.001$ & 1.45 (1.22 to 1.71$)$ & $<0.001$ \\
\hline History of hypertension & 1.20 (1.03 to 1.40$)$ & 0.021 & $1.00(0.82$ to 1.21$)$ & 0.994 \\
\hline History of peripheral vascular disease* & 1.85 (1.46 to 2.35$)$ & $<0.001$ & - & \\
\hline History of cerebrovascular disease* & 1.70 (1.26 to 2.29$)$ & 0.001 & - & \\
\hline Increased creatinine (> $200 \mathrm{~mol} / \mathrm{L}$ ) & 4.01 (2.75 to 5.85$)$ & $<0.001$ & 2.56 (1.64 to 3.99$)$ & $<0.001$ \\
\hline LV systolic dysfunction & 1.57 (1.38 to 1.78$)$ & $<0.001$ & 1.36 (1.18 to 1.56$)$ & $<0.001$ \\
\hline History of previous myocardial infarction & 1.21 (1.04 to 1.40$)$ & 0.011 & 1.15 (0.97 to 1.36$)$ & 0.113 \\
\hline \multicolumn{5}{|l|}{ Angiographic variables } \\
\hline Syntax score (per unit) & 1.03 (1.02 to 1.04$)$ & $<0.001$ & $1.02(1.01$ to 1.03$)$ & $<0.001$ \\
\hline Severe lesion calcification & 1.86 (1.60 to 2.16$)$ & $<0.001$ & 1.23 (1.02 to 1.49$)$ & 0.031 \\
\hline
\end{tabular}

*Because of missing data, the history of cerebrovascular and peripheral vascular disease was not entered into the multivariate analysis. 
Table 5 Univariate and multivariate Cox regression analysis of variables associated with death—myocardial infarction—any revascularisation.

\begin{tabular}{|c|c|c|c|c|}
\hline & \multicolumn{2}{|c|}{ Univariate Cox regression } & \multicolumn{2}{|c|}{ Multivariate Cox regression* } \\
\hline & HR (95\% Cl) & $\mathrm{p}$ Value & HR (95\% Cl) & $\mathrm{p}$ Value \\
\hline Increasing age (per decade) & 1.14 (1.08 to 1.20$)$ & $<0.001$ & $1.08(1.02$ to 1.16$)$ & 0.013 \\
\hline \multicolumn{5}{|l|}{ Comorbidity } \\
\hline History of diabetes mellitus & 1.52 (1.35 to 1.72$)$ & $<0.001$ & 1.42 (1.23 to 1.64$)$ & $<0.001$ \\
\hline History of hypertension & $1.23(1.08$ to 1.40$)$ & 0.002 & 1.07 (0.91 to 1.25$)$ & 0.431 \\
\hline History of peripheral vascular disease* & 1.44 (1.15 to 1.82$)$ & 0.002 & - & \\
\hline Increased creatinine (>200 mol/L) & 2.76 (1.91 to 3.99$)$ & $<0.001$ & 2.04 (1.33 to 3.14$)$ & 0.001 \\
\hline LV systolic dysfunction & 1.25 (1.11 to 1.41$)$ & $<0.001$ & 1.15 (1.02 to 1.31$)$ & 0.026 \\
\hline Previous history of myocardial infarction & 1.17 (1.04 to 1.32$)$ & 0.010 & 1.07 (0.93 to 1.23$)$ & 0.335 \\
\hline \multicolumn{5}{|l|}{ Angiographic variables } \\
\hline Syntax score (per unit) & 1.03 (1.02 to 1.03$)$ & $<0.001$ & $1.03(1.02$ to 1.03$)$ & $<0.001$ \\
\hline Severe lesion calcification & 1.52 (1.34 to 1.72$)$ & $<0.001$ & 1.18 (1.01 to 1.39$)$ & 0.042 \\
\hline First generation stent & $1.15(0.98$ to 1.35$)$ & 0.091 & 1.13 (0.90 to 1.41$)$ & 0.289 \\
\hline
\end{tabular}

A potential explanation of this finding is that coronary calcification is a marker of extensive atherosclerotic disease. Indeed, several electron beam-computed tomography-based studies have shown that coronary calcification is a predictor of atherosclerosis progression and is related with increased cardiovascular mortality in the general population. ${ }^{20}{ }^{21}$ However, in patients undergoing PCI, the focus has been towards the development of anatomical scores that would allow accurate assessment of lesion complexity, or the implications of the lesion on myocardial perfusion and the prognostic value of coronary calcification has been ignored. ${ }^{16} 22$ The present study convincingly demonstrates that severe lesion calcification provides additional information which, until today, has been neglected and not been taken into consideration in the prognostic models developed for patients undergoing PCI. ${ }^{23} 24$

Severe lesion calcification appeared to be associated with an increased risk of ST in univariate analysis, but it was not an independent predictor of ST. Our results are different from the findings of other reports which showed that lesion calcification is independently associated with an increased risk of ST, ${ }^{6}$ but are similar to the findings of the SYNTAX study, that included the Syntax score, which can compete with lesion calcification in the multivariate model. ${ }^{25}$ Nevertheless, the fact that this study did not include procedural information (ie, number of implanted stents, length and diameter of stents, etc), lesion characteristics (ie, length of the lesion, vessel diameter, the number of the bifurcated lesions), and the type and duration of antiplatelet treatment, does not allow us to draw firm conclusions about the factors related to ST.

We have recently demonstrated that patients suffering from coronary artery disease with severely calcified lesions are more likely to receive suboptimal revascularisation and have a higher residual Syntax score which is a powerful determinant of prognosis. ${ }^{26}$ Additionally, in this study, we found that patients with severely calcified lesions are less likely to have undergone complete revascularisation. A decalcification strategy with extensive metallic stent implantation cannot be justified as there is robust evidence that stent length is a predictor of TLR. On the other hand, bioresorbable scaffolds appear to overcome the limitations of the traditional metallic stents and seem to have a role for the treatment of heavily calcified lesions. ${ }^{27}$ Whether complete revascularisation-implementing a decalcification strategy of longcalcified lesions with atherectomy, or the recently introduced orbital atherectomy system followed by bioresorbable scaffold implants-would improve outcomes in this high-risk population, needs to be proven by future studies. ${ }^{28}$

\section{Study limitations}

Several intravascular imaging studies have shown that coronary angiography has a limited sensitivity in detecting the presence of calcified plaques. ${ }^{17} 29$ However, it has a high specificity for detecting severe calcification, and has been shown in this study to provide useful prognostic information. By contrast with previous studies which implemented a more thorough classification scheme for characterising lesion calcification, we decided to classify patients in a binary fashion to those who have lesions with none/mild/moderate calcification, and those with severe calcification. Although this may be regarded initially as a limitation of the current analysis, our decision was based on the low intraobserver and interobserver variability reported for the discrimination between none/mild and moderate/severe calcification. ${ }^{30}$ Of note, Genereux et $a l^{31}$ have shown that experts can identify and differentiate with a high agreement severely calcified lesions from the other lesions; based on these findings, we decided to use a reproducible metric and divide patients based on the presence of severe calcification.

Finally, a significant limitation of this study is the fact that the medications data, such as the type of medications, the doses and the duration of treatment (especially the duration of dual antiplatelet treatment), as well as procedural data (ie, treatment of bifurcation lesions, length of the lesions, vessel diameter, number of implanted stents, dimensions of the stents, etc) were not available.

\section{CONCLUSIONS}

Patients with severely calcified lesions are at a high risk of experiencing a cardiovascular event. Severe lesion calcification appears to provide additional prognostic information to the Syntax score, which reflects lesion complexity, because it is a marker of extensive atherosclerosis, and because patients with severely calcified lesions do not receive complete revascularisation. Further research is needed to explore whether a decalcification strategy and complete revascularisation of these high-risk patients would have a beneficial effect on their prognosis. 
Key messages

What is known on this subject?

There is strong evidence demonstrating that lesion calcium is associated with an increased risk of target vessel revascularisation following bare-metal or drug-eluting stent implantation. However, there are limited data regarding the impact of lesion calcium on hard clinical end-points in the drug-eluting stents era.

\section{What might this study add?}

This study shows that the patients with severely calcified lesions who undergo percutaneous coronary intervention $(\mathrm{PCI})$ with a first-generation or a second-generation drug-eluting stent often undergo incomplete revascularisation and have worse clinical outcomes compared to those without severe coronary calcification.

\section{How might this impact on clinical practice?}

All the previous risk models that were designed to predict prognosis in patients undergoing $\mathrm{PCl}$ did not take into account lesion calcification. This study is anticipated to trigger the re-evaluation of the existing risk scores and the design of new models that would predict patients' prognosis with a higher accuracy.

\author{
Author affiliations \\ ${ }^{1}$ Thoraxcenter, Erasmus Medical Center, Rotterdam, The Netherlands \\ ${ }^{2}$ Department of Cardiology, East Lancashire NHS Trust Blackburn, Lancashire, UK \\ ${ }^{3}$ Department of Interventional Cardiology, Bern University Hospital, Bern, \\ Switzerland \\ ${ }^{4}$ Herzzentrum, Leipzig, Germany \\ ${ }^{5}$ Heart Center at the Isar, Munich, Germany \\ ${ }^{6}$ Cardialysis BV, Rotterdam, The Netherlands \\ ${ }^{7}$ International Centre for Circulatory Health, NHLI, Imperial College London, \\ London, UK
}

Contributors CVB and PWS: designed and planned the study, interpreted the data and drafted the manuscript. CVB, Y-JZ and M-AM: merged and analysed the data. The other authors: revised it critically for important intellectual content and gave final approval of the version to be published.

Funding The first author is funded by the Hellenic Heart Foundation.

Competing interests None.

Patient consent Obtained.

Ethics approval All studies complied with the Declaration of Helsinki and were approved by the ethical review board of the institution involved, whereas, the included patients provided written informed consent for participation in these studies.

Provenance and peer review Not commissioned; externally peer reviewed.

\section{REFERENCES}

1 Savage MP, Goldberg S, Hirshfeld JW, et al. Clinical and angiographic determinants of primary coronary angioplasty success. M-HEART Investigators. J Am Coll Cardiol 1991;17:22-8.

2 Moussa I, Di Mario C, Moses J, et al. Coronary stenting after rotational atherectomy in calcified and complex lesions. Angiographic and clinical follow-up results. Circulation 1997;96:128-36.

3 Moussa I, Ellis SG, Jones $\mathrm{M}$, et al. Impact of coronary culprit lesion calcium in patients undergoing paclitaxel-eluting stent implantation (a TAXUS-IV sub study). Am J Cardiol 2005;96:1242-7.

4 Onuma $Y$, Tanimoto $S$, Ruygrok $P$, et al. Efficacy of everolimus eluting stent implantation in patients with calcified coronary culprit lesions: two-year angiographic and three-year clinical results from the SPIRIT II study. Catheter Cardiovasc Interv 2010;76:634-42.

5 Costa JR Jr, Sousa A, Moreira AC, et al. Incidence and predictors of very late ( $>$ or $=4$ years) major cardiac adverse events in the DESIRE (Drug-Eluting Stents in the Real World)-Late registry. JACC Cardiovasc Interv 2010;3:12-18.
6 Lasala JM, Cox DA, Dobies D, et al. Drug-eluting stent thrombosis in routine clinical practice: two-year outcomes and predictors from the TAXUS ARRIVE registries. Circ Cardiovasc Interv 2009;2:285-93.

7 Kawaguchi R, Tsurugaya $\mathrm{H}$, Hoshizaki $\mathrm{H}$, et al. Impact of lesion calcification on clinical and angiographic outcome after sirolimus-eluting stent implantation in real-world patients. Cardiovasc Revasc Med 2008;9:2-8.

8 Fujimoto H, Nakamura M, Yokoi H. Impact of calcification on the long-term outcomes of sirolimus-eluting stent implantation: subanalysis of the Cypher Post-Marketing Surveillance Registry. Circ J 2012;76:57-64.

9 Serruys PW, Morice MC, Kappetein AP, et al. Percutaneous coronary intervention versus coronary-artery bypass grafting for severe coronary artery disease. $N$ Engl J Med 2009;360:961-72.

10 Serruys PW, Silber S, Garg S, et al. Comparison of zotarolimus-eluting and everolimus-eluting coronary stents. N Engl J Med 2010;363:136-46.

11 Windecker S, Remondino A, Eberli FR, et al. Sirolimus-eluting and paclitaxel-eluting stents for coronary revascularization. N Engl J Med 2005;353:653-62.

12 Windecker S, Serruys PW, Wandel S, et al. Biolimus-eluting stent with biodegradable polymer versus sirolimus-eluting stent with durable polymer for coronary revascularisation (LEADERS): a randomised non-inferiority trial. Lancet 2008;372:1163-73.

13 Serruys PW, Ong AT, Morice MC, et al. Arterial Revascularisation Therapies Study Part II-Sirolimus-eluting stents for the treatment of patients with multivessel de novo coronary artery lesions. Eurolntervention 2005;1:147-56.

14 Valgimigli M, Percoco G, Malagutti P, et al. Tirofiban and sirolimus-eluting stent vs abciximab and bare-metal stent for acute myocardial infarction: a randomized trial. JAMA 2005;293:2109-17.

15 Valgimigli M, Campo G, Percoco G, et al. Comparison of angioplasty with infusion of tirofiban or abciximab and with implantation of sirolimus-eluting or uncoated stents for acute myocardial infarction: the MULTISTRATEGY randomized trial. JAMA 2008;299:1788-99.

16 Sianos G, Morel MA, Kappetein AP, et al. The SYNTAX Score: an angiographic tool grading the complexity of coronary artery disease. Eurolntervention 2005;1:219-27.

17 Mintz GS, Popma JJ, Pichard AD, et al. Patterns of calcification in coronary artery disease. A statistical analysis of intravascular ultrasound and coronary angiography in 1155 lesions. Circulation 1995;91:1959-65.

18 Garg S, Sarno G, Girasis C, et al. A patient-level pooled analysis assessing the impact of the SYNTAX (synergy between percutaneous coronary intervention with taxus and cardiac surgery) score on 1-year clinical outcomes in 6,508 patients enrolled in contemporary coronary stent trials. JACC Cardiovasc Interv 2011;4:645-53.

19 Cutlip DE, Windecker S, Mehran R, et al. Clinical end points in coronary stent trials: a case for standardized definitions. Circulation 2007;115:2344-51.

20 Folsom AR, Kronmal RA, Detrano RC, et al. Coronary artery calcification compared with carotid intima-media thickness in the prediction of cardiovascular disease incidence: the Multi-Ethnic Study of Atherosclerosis (MESA). Arch Intern Med 2008;168:1333-9.

21 Shemesh J, Morag-Koren N, Goldbourt U, et al. Coronary calcium by spiral computed tomography predicts cardiovascular events in high-risk hypertensive patients. J Hypertens 2004;22:605-10.

22 Leaman DM, Brower RW, Meester GT, et al. Coronary artery atherosclerosis: severity of the disease, severity of angina pectoris and compromised left ventricular function. Circulation 1981;63:285-99.

23 Farooq V, Vergouwe $Y$, Raber $L$, et al. Combined anatomical and clinical factors for the long-term risk stratification of patients undergoing percutaneous coronary intervention: the Logistic Clinical SYNTAX score. Eur Heart J 2012;33:3098-104.

24 Garg S, Sarno G, Garcia-Garcia HM, et al. A new tool for the risk stratification of patients with complex coronary artery disease: the Clinical SYNTAX Score. Circ Cardiovasc Interv 2010;3:317-26.

25 Faroog V, Serruys PW, Zhang Y, et al. Short-term and long-term clinical impact of stent thrombosis and graft occlusion in the SYNTAX trial at 5 years: Synergy Between Percutaneous Coronary Intervention with Taxus and Cardiac Surgery trial. J Am Coll Cardiol 2013;62:2360-9.

26 Faroog V, Serruys PW, Bourantas CV, et al. Quantification of incomplete revascularization and its association with five-year mortality in the synergy between percutaneous coronary intervention with taxus and cardiac surgery (SYNTAX) trial validation of the residual SYNTAX score. Circulation 2013;128:141-51.

27 Basavarajaiah S, Naganuma T, Latib A, et al. Can bioabsorbable scaffolds be used in calcified lesions? Catheter Cardiovasc Interv 2013;16.

28 Parikh K, Chandra P, Choksi N, et al. Safety and feasibility of orbital atherectomy for the treatment of calcified coronary lesions: the ORBIT I trial. Catheter Cardiovasc Interv 2013;81:1134-9.

29 Tuzcu EM, Berkalp B, De Franco AC, et al. The dilemma of diagnosing coronary calcification: angiography versus intravascular ultrasound. J Am Coll Cardiol 1996:27:832-8

30 Herrman JP, Azar A, Umans VA, et al. Inter- and intra-observer variability in the qualitative categorization of coronary angiograms. Int I Card Imaging 1996;12:21-30

31 Genereux P, Palmerini T, Caixeta A, et al. SYNTAX score reproducibility and variability between interventional cardiologists, core laboratory technicians, and quantitative coronary measurements. Circ Cardiovasc Interv 2011;4:553-61. 


\title{
Heart
}

Prognostic implications of coronary calcification in patients with obstructive coronary artery disease treated by percutaneous coronary intervention: a patient-level pooled analysis of 7 contemporary stent trials

Christos V Bourantas, Yao-Jun Zhang, Scot Garg, Javaid lqbal, Marco Valgimigli, Stephan Windecker, Friedrich W Mohr, Sigmund Silber, Ton de Vries, Yoshinobu Onuma, Hector M Garcia-Garcia, Marie-Angele Morel and Patrick W Serruys

Heart 2014 100: 1158-1164 originally published online May 20, 2014 doi: 10.1136/heartjnl-2013-305180

Updated information and services can be found at: http://heart.bmj.com/content/100/15/1158

\begin{abstract}
These include:
References This article cites 30 articles, 9 of which you can access for free at: http://heart.bmj.com/content/100/15/1158\#BIBL
\end{abstract}

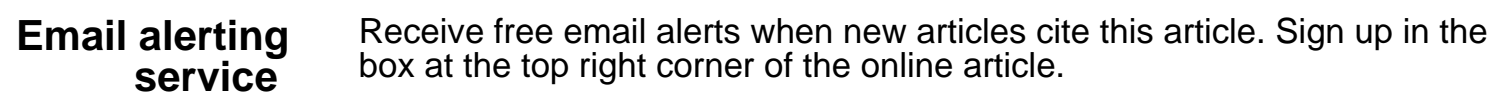

Collections

Articles on similar topics can be found in the following collections

Interventional cardiology (2866)

Drugs: cardiovascular system (8597)

Epidemiology (3619)

Percutaneous intervention (939)

Acute coronary syndromes (2673)

Clinical diagnostic tests (4685)

Venous thromboembolism (479)

\section{Notes}

To request permissions go to:

http://group.bmj.com/group/rights-licensing/permissions

To order reprints go to:

http://journals.bmj.com/cgi/reprintform

To subscribe to BMJ go to:

http://group.bmj.com/subscribe/ 